\title{
TENDENCIAS ACTUALES EN LA TRADUCCIÓN DE TÍTULOS DE OBRAS DE ARTE PLÁSTICO \\ $M^{a}$ Luisa Rodríguez Muñoz \\ Universidad de Córdoba
}

\begin{abstract}
This article aims to present certain conclusions on a very specific group, as is the profile of students wishing to study Translation and Interpretation. Therefore, the aim is to make an initial outline of the expectations and motivations of future Translation and Interpretation candidate students, by trying to identify their needs, fears, false conceptions and expectations.
\end{abstract}

KEYWORDS: student, translation, interpretation, expectations, needs.

\section{RESUMEN}

El presente artículo analiza un pequeño cultivo dentro del inmenso ámbito de la traducción de arte centrándose en las técnicas empleadas para la exportación de títulos de las obras a otras culturas. Con él, pretendemos diagnosticar la presente situación, mediante apuntes teóricos procedentes de las corrientes traductológicas más modernas, entre las que destacan, el giro cultural de la traducción y vislumbrar así cómo alertar sobre las posibles tendencias en el futuro a corto y medio plazo en este campo.

PALABRAS CLAVE: traducción de arte, obra de arte, técnicas, corrientes traductológicas.

\section{INTRODUCCIÓN}

Bienales, ferias, museos, exposiciones, pintadas, luminosos que nos asaltan en cualquier rincón de la ciudad. El arte posmoderno es una manifestación más de la escena global en el que la comunicación estética supera barreras físicas, geográficas y "normativas" en cuanto a forma y fondo. El crecimiento innegable del consumo de lo artístico en la actualidad y la internacionalización de este fenómeno nos invita a reflexionar sobre el papel que desempeña la traducción en un ámbito de propuestas cada vez más 
arriesgadas en el que el mensaje lingüístico ha pasado de ser una simple etiqueta a convertirse en recurso expresivo al servicio de la obra o, incluso, en el protagonista de la misma.

La tendencia acusada de emplear la palabra como técnica de arte se inserta en la transformación de los cánones estéticos acontecida en el mundo del arte, durante el S. XX, momento en el que la propensión innata a la mímesis de la obra artística, acompañada generalmente de títulos casi unívocos, se revierte con la máxima del "arte por el arte": lo representado ya no es fácilmente reconocible y los títulos se muestran como la llave maestra para acceder a los significados de las obras o incrementar la carga semántica de lo expresado por el artista, que es cada vez más consciente del poder sugerente de la palabra. Movimientos como el arte conceptual o el video-art, en el que se recurre al subtitulado, sitúan a la traducción en un lugar privilegiado en la exportación de arte.

El presente artículo analiza un pequeño cultivo dentro del inmenso ámbito de la traducción de arte centrándose en las técnicas empleadas para la exportación de títulos de las obras a otras culturas. Con él, pretendemos diagnosticar la presente situación, mediante apuntes teóricos procedentes de las corrientes traductológicas más modernas, entre las que destacan, el giro cultural de la traducción y vislumbrar así como alertar sobre las posibles tendencias en el futuro a corto y medio plazo en este campo.

A modo de introducción, vamos a definir el objeto de estudio desde diversas perspectivas a fin de poner de relieve la enorme cantidad de factores que condicionan la labor del traductor de títulos de arte.

\section{EL TÍTULO DE LA OBRA DE ARTE: UN NOMBRE PROPIO.}

Según el DRAE, un título es, en primer lugar, una palabra o frase con que se da a conocer el nombre o asunto de una obra o de cada una de las partes o divisiones de un escrito. Por consiguiente, el título de una obra de arte será la "etiqueta", la fórmula lingüística mediante la que reconocemos y diferenciamos esa composición de las demás, es decir, su nombre propio, el que, sin tener rasgos semánticos inherentes, se aplica a seres animados o inanimados para designarlos.

A decir de esta definición, carecería de sentido cuestionarnos el tema de la traducción de nombres propios porque, a los ojos de la Academia, sólo realizan una función deíctica. No obstante, la práctica misma de la traducción desmiente este simplismo. Hoy en día son muchos los expertos que defienden la postura de que los nombres propios poseen, incluso, una semántica más rica que la de los nombres comunes (Cuéllar, 2004). El libro del Buen Amor, La libertad guiando al pueblo o El paciente inglés poseen un significado perfectamente analizable, que sirve para describir el referente al que da nombre (Franco Aixelá, 2000). Son los 
llamados nombres propios "expresivos", "semánticos" o "transparentes", susceptibles, incluso de forma descontextualizada, de definición y traducción que tanto proliferan en el mundo del arte.

\section{EL TÍTULO COMO REPRESENTACIÓN SUBORDINADA}

El título es una representación lingüística condicionada por su referente plástico. Por consiguiente, llevar a cabo una traducción en el ámbito que nos ocupa supone, al menos, un doble ejercicio de interpretación: mediar entre lenguas (traducción interlingüística) y entre códigos (el de las formas, el color, las texturas, las imágenes...y el lenguaje). Es decir, el poder semiótico del macrosigno artístico surge del entrelazado de múltiples mimbres que sobrepasan los límites de un marco colgado en la pared de un museo. El código lingǘstico deja de ser el protagonista del mensaje, considerado como un todo semiótico, cuyo contenido es un discurso a varios niveles, y pasa a depender con mayor o menor grado de servidumbre, del objeto de arte. Podemos hablar, por tanto, de una forma más de "traducción subordinada" que plantea algunas cuestiones similares a las que puedan suscitarse en el proceso de "exportación" de cómics o anuncios publicitarios en prensa:

- Limitación del espacio destinado a la escritura. Por poner un ejemplo, el título de una obra perteneciente a un catálogo de arte se caracteriza por su brevedad como el texto de un bocadillo de una viñeta de tebeo. Muchas connotaciones del lenguaje deben simplificarse porque los juegos idiomáticos o las referencias culturales serían, en ocasiones, intraducibles sin el recurso de la nota del traductor o la introducción teórica al universo cultural, artístico y personal del artista.

Armonización entre imagen y texto. La presencia de varios códigos requiere la coherencia entre ellos o, si el autor lo quiere así, la "incoherencia" alevosa como recurso para captar la atención del lector o

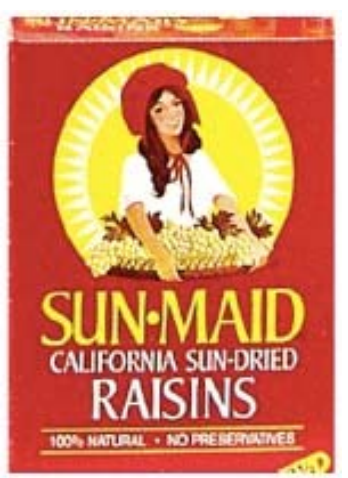
espectador.

Presencia de referentes culturales. Los autores de las obras de arte están influenciados por las circunstancias y las experiencias que viven de manera personal. Sus obras son producto de su visión del mundo condicionada por las coordenadas espaciotemporales en las que trabajan, por lo que sus representaciones y los títulos de las mismas pueden ser comprensibles para un determinado público ideal para el que se crea pero opacas o inaprensibles para nuevos receptores de culturas extranjeras. Los traductores de arte se enfrentan al reto de traducir cultura. 
Ilustremos este punto con la obra Sun Mad de Esther Hernández publicada en nuestro país (Nuez Santana, 2001) con el título transferido. El formato que sigue la imagen simula el de un anuncio. Si indagamos sobre el mensaje que subyace a la representación, descubrimos que el nombre de este "cartel publicitario" es un juego de palabras y el significado, una parodia del logo de una empresa estadounidense de pasas, Sun Maid, desconocida para el público español. Sin este referente cultural, el receptor meta no podrá acceder a parte del contenido

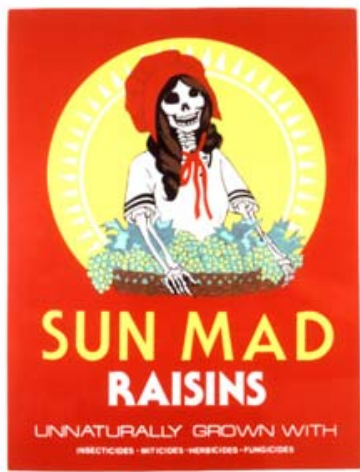
de lo representado y por tanto, se le escapará el guiño cultural y la denuncia del sistema que, según declaraciones de la artista, se pretende.

Presencia de recursos literarios con los que emocionar. Algunos títulos de obras de arte contemporáneo se han convertido en auténticos eslóganes publicitarios, muy sugerentes, tan creativos que forman parte de trabajo al que denominan como si la imagen que sustentan estuviera a medio hacer sin su presencia. Los artistas se valen de recursos literarios para "fijar" la marca de sus trabajos en la mente del receptor: rima (L'amour, c'est comme un tour. Carlos Pazos), paradojas (Iceberg Tropical. Luis Gordillo), juegos de palabras (Décalage de cafés o décalés de calaix. C. Pazos), inclusión de frases célebres de la literatura (Off with Her Head,. A. Morell), adjetivación sugerente (El rutilante quehacer de los inapreciables termina aburriendo a Chelo. Juan Carlos Román) o apelación directa mediante el uso de la $2^{\mathrm{a}}$ persona del singular (How dare you not be me? Barbara Kruger).

\section{EL TÍTULO COMO SIGNO}

Insertos simultáneamente en una cultura, en un movimiento artístico, en la obra de un autor, en una exposición, en una plasmación plástica, los títulos de las obras de arte son la última muñeca de una gran matrioska cultural, que reflejan, en escala, los atributos de ésta.

Desde el punto de vista de la semiótica (Eco, 1971), la cultura en su sentido más amplio se retrata como un fenómeno de significación y de comunicación o producción de signos. Así pues, las unidades que la componen son vistas como postulados de una ecuación entre códigos que la sociedad realiza continuamente, una eterna correlación entre formas y contenidos que dan sustancia al "todo cultural". Ciertamente, vivimos inmersos en un mundo de signos, es decir, de cosas que pueden considerarse como sustitutos significantes de otras en virtud, siempre, de una convención. Toda manifestación resulta, a la postre, un signo que invoca a una realidad, presente o no en el momento de su generación. Deducimos que, 
en lo que respecta a la cuestión que nos compete en el presente estudio, el título original, sus traducciones, la obra y sus remakes en otras épocas son representaciones de una misma idea mental y coinciden en su naturaleza de "signo", de reflejo de la realidad. Por tanto, se convierten todos en "originales"

En esta línea, la traducción es concebida como una forma más de representación o de reescritura (Lefevère), sometida a una serie de condicionantes, códigos y normas que constituyen los sistemas imperantes en una sociedad. Tales convenciones, mutan con el tiempo y el espacio; se sitúan como campos de fuerzas que hay que penetrar para llegar al otro y a los signos que concibió en un entorno extraño de traducciones entrelazadas del mundo. La señal artística, de la que el título forma parte, requiere siempre una respuesta interpretativa para no ser un simple estímulo que, en el caso de la exportación de arte, aúna el esfuerzo hermenéutico y previsor del traductor con la recepción y reelaboración del sentido por parte del destinatario.

\section{ELEMENTOS DEL ACTO DE COMUNICACIÓN EN LA TRADUCCIÓN DE ARTE}

Dentro de las formas de comunicación visual, el arte siempre tiene una intención (Munari, 1985). El signo artístico no es casual, busca una respuesta del espectador, es decir, requiere una interpretación, una reacción interna ante lo expresado. Este paso no es más que el final de un proceso comunicativo mucho más complejo que el simple intercambio de información emisormensaje-receptor: la comunicación visual es, ante todo, una construcción de sentido interactiva e intercultural (Goyes Narváez, 2002).

En el caso de la exportación y recepción de arte a nuevas culturas, la intervención del traductor complica la acción comunicativa incluyendo nuevas fases en el proceso. En este diálogo significativo, el mediador debe tomar conciencia de los elementos que intervienen para desempeñar su labor con una mayor calidad y presentar un producto aceptable en la cultura meta:

1. La cultura origen. Entendemos el concepto "cultura" en su sentido colectivo a la luz de la distinción que realiza Ortega Arjonilla (Ortega Arjonilla, 2006) sobre las acepciones del término. De esta forma, "la cultura origen" comprende el conjunto de modos de vida y costumbres, conocimientos y grado de desarrollo artístico, científico, industrial que constituye la situación dada de acerbo cultural del grupo humano contemporáneo al artista del que él forma parte. Por tanto, se establece como el prisma desde el que la obra adquiere sentido por comulgar con los usos y costumbres de un determinado grupo social o por desafiarlos (la contracultura).

2. El artista. Es el iniciador del proceso. Elabora el mensaje a través de varios códigos para un receptor ideal con mayor o menor grado de 
sensibilidad artística. Su obra se desarrolla en un cierto contexto biográfico y socio-cultural, sometida a los cánones artísticos imperantes en el momento. El traductor no puede perder de vista este sujeto para poder comprender la composición y salvaguardar, en la medida de lo posible, la fidelidad al original.

3. La obra. Es el mensaje. Puede ser más o menos abierto, por explicitud, o presentar una inagotable riqueza de opciones posibles en un ejercicio de códigos cruzados (imagen, movimiento, color, formas, textura, texto en uno o varios idiomas...). Está sometida a las constricciones del periodo en que se ejecuta, a las normas artísticas y al universo de propuestas de arte que se desarrollan en una época determinada (Lefevere). Cada receptor actualizará, dependiendo de sus conocimientos y circunstancias, una obra diferente. La original nace en unas coordenadas temporales-espaciales con un objetivo claro cuyo conocimiento orientará la comprensión del traductor.

4. El traductor. Es el intermediario cultural. Desempeña la labor de receptor primario, con su propia concepción del mundo, y reescritor de títulos o segundo artista de la obra en cuestión, dependiendo de la importancia que cobre el lenguaje en la pieza que se desea exportar. Su labor está sometida a los dictados de los patrones o curadores de la exposición o publicación, las normas de "presentación" y "traducción" de títulos de la cultura meta, el deseo del autor (que a veces es explícito), las posibilidades del formato en que se expresa... Sobre él recae la responsabilidad de exportar cultura Más o menos "adulterada", decidiendo entre facilitar la comprensión de la obra, a través de títulos fluidos, o presentar el trabajo en estado puro. El traductor intentará anticipar el efecto que sus decisiones pueden llevar a cabo en el receptor meta mediante previsiones basadas en los datos de los que dispone sobre el contexto en que la obra va a ser mostrada.

5. La cultura meta. Es la cultura receptora de la obra de arte elaborada en otro contexto. Posee sus propias reglas y convenciones con las que están familiarizados los nuevos destinatarios de la apuesta artística. Conocer este sistema hacia el que se traduce permite orientar las decisiones con mayor fiabilidad.

6. La obra meta. Es la obra exportada. En ella la imagen u objeto se mantiene aunque presenta una nueva envoltura lingüística. El traductor "manipula" el arte para insertarlo en un nuevo contexto.

7. El receptor meta. Es el público perteneciente a la sociedad en la que se expone la obra meta que va a descodificarla. Desde su "forma de ser en el mundo" (Ladmiral) mira y filtra la muestra de arte recreando su propia obra mental, reescribiendo su original.

Todos estos elementos contribuyen a hacer de las traducciones realidades dinámicas que no pueden analizarse sino desde una posición abierta en la que tengan cabida muchos factores extralingüísticos. 


\section{ANÁLISIS DESCRIPTIVO DE LAS ESTRATEGIAS DE TRADUCCIÓN DE LOS TÍTULOS EN LA IMPORTACIÓN DE ARTE PLÁSTICO}

El análisis que desarrollamos a continuación se basa en ciertos criterios de la clasificación de estrategias de traducción de nombres propios desde una perspectiva cultural realizada por Javier Franco Aixelá (Franco Aixelá, 2000) completados por los parámetros establecidos en el artículo "La Traducción del arte: una operación de mediación intercultural 'estéticamente' condicionada" de Emilio Ortega Arjonilla (Ortega Arjonilla, 2006).

En primer lugar, hemos de señalar que las técnicas empleadas en el corpus estudiado pertenecen a dos grandes grupos: las de conservación y las de sustitución parcial o completa de los mensajes lingüísticos en el acto de exportación y recepción de obras de arte.

\subsection{LA CONSERVACIÓN}

En términos netamente lingüísticos, la conservación no representa ninguna modificación representativa de la materia de trabajo, esto es, la palabra en la lengua de origen. No obstante, podemos decir que la "no traducción" en un contexto concreto y dirigida a un público diferente al originario supone una nueva forma de significar, un grado más dentro del amplio espectro de posibilidades de reescritura. Distinguimos en este grupo tres estrategias de traducción: la repetición, la adaptación ortográfica y terminológica y la glosa intra y extratextual.

En cuanto al primer recurso se refiere, la repetición, hemos detectado que se emplea principalmente en los siguientes contextos: ferias y galerías internacionales de arte, venta de arte y modas del arte contemporáneo, traducción de movimientos lingüísticos y sociales "mestizos", exportación de localismos y topónimos, tratamiento de juegos de palabras y letras de canciones, transferencia de obras universales y de aquellas en las que el título se inserta en el interior de la composición.

Pongamos algunos ejemplos:

1. Ferias y galerías internacionales: la repetición del inglés como lengua vehicular del arte contemporáneo en ARCO 2006.

- Golden sunshine. He Yunchaung. (China)

- The absent presence. Hussein Chalayan. (Turquía).

- Drops. Hiroshi Oashi. (Japón)

- Painting. Rostan Tavasiev (Rusia).

- Enter your dreams. Pauline Fondevila (Francia). 
- $\quad$ Food for peace. Fernando Bryce (Perú).

2. Venta y exposición de arte contemporáneo: la repetición del inglés y francés por motivos de marketing y moda.

- Melting Pot. Pedro Uhart. En www.pedro-uhart.com.

- Bañista "plein soleil". Luis Gordillo. Exposición "Iceberg Tropical: Antológica 1959-2007”. Museo Nacional Centro Reina Sofía. Del 27-03-2007 al 20-08-2007.

- Shadows de sombras. Carlos Pazos. Museu de la Música (Barcelona, 1999).

- Deplacement electrique. Marta Boto. Exposición "Lo[s] cinético[s]". Museo Ce qui n'est pas nomé. Darío Álvarez Basso. Centro Galego de Arte Contemporánea (CGAC).

3. Traducción de movimientos sociales y lingüísticos mestizos: repetición en el arte chicano en contextos anglosajones e hispanos como preservación de una ideología.

- Bato con Sunglasses. César Martínez. En Trends in Postmodern Art. http://www.eyeconart.net/history/postmodern.htm.

- Luna Llena/Full Moon. Esther Hernández. Página personal en inglés de la artista: www.estherhernandez.com.

- Humanscape 141: Barrio Dog. Melesio Casas. En la exposición itinerante "Chicano Visions: American Painters on the Verge”. EEUU.

- Ayi! Dream of Chicos Corazon. Leo Limón. En la exposición itinerante "Chicano Visions: American Painters on the Verge". EEUU.

4. Exportación de localismos y topónimos: repetición de lo "culturalmente marcado" y el mantenimiento de los nombres propios en un contexto turístico.

- La Grande Corrida avec Femme Torero. Pablo Picasso. Fitzwilliam Museum (Cambridge)..

- Seguidilla. Man Ray. National Gallery of Art (Washington).

- Maestà. Duccio. Enciclopedia Britannica.

- Koré. Museo de Bellas Artes de Lyón.

- San Pietro in Montorio. Guía Italia. Lonely Planet.

- The Maison Carrée. En la página web de turismo de la ciudad de Nîmes en su versión inglesa.

5. Tratamiento de juegos de palabras y letras de canciones: la opacidad para la comunidad receptora de los juegos del lenguaje y la intertextualidad en los títulos.

- Basketbrawl. Tom Sanford. Catálogo de ARCO 2006. 
- Collage / l'âge de la colle. Man Ray. "Batman entre las mariposas. Arte coleccionista o el riesgo de transgredir el orden sin tregua". En el catálogo de la exposición de Carlos Pazos "No me digas nada", 2007.

- Ivette cantando "Linger, longer, loo". Toulouse Lautrec.

- We can be heros just for one day [canción de David Bowie]. Marie Jo La Fontaine.

6. Transferencia de obras universales: los "intraducibles del arte"

- Macchu Pichu, Taj-Mahal, Chichén Itzá, Alhambra, Kiyomizu-dera, Abu-Simbel, Ara Pacis, Stonehenge.

7. La repetición cuando el título de la obra aparece dentro de ella:

- Hay que seguir creciendo. R. Diago. Virginia Miller Galleries (Florida). [se representa una planta en pleno crecimiento al pie de la que reza "hay que seguir creciendo"].

- Fabulous things bappen. V. Rodríguez. [serie de representaciones a las que el propio autor cuelga un título elaborado].

La segunda de las estrategias, la adaptación ortográfica y terminológica, abarca aquellos casos en los que el nombre original se mantiene aunque con ciertas modificaciones en su forma por la propia idiosincrasia fonética de las lenguas de las comunidades que acogen a las obras:

- The Angelus (EN), el Ángelus (ES), l'Angélus (FR). Millet.

- $\quad$ The Discobolos (EN), el Discóbolo (ES), le Discobole (FR).

- The Parthenon (EN), el Partenón (ES), le Partenon (FR)

- Las Meninas (ES), les Ménines (FR).

Finalmente, la glosa intra y extratextual se utiliza para explicar elementos marcados culturalmente, títulos extranjerizados intencionalmente o mensajes clave del arte verbal que, aunque no aparecen traducidos en sala, se describen en catálogos y webs que publicitan las obras para el público en general. 


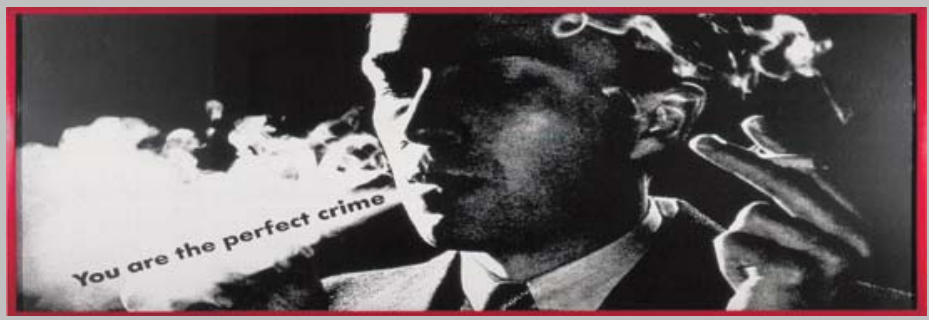

\section{You are the perfect crime. Barbara Kruger. Fonds Régionaux d'Art Contemporain de Bourgogne.}

Ainsi « You are the perfect crime », phrase déclarative, semble s'adresser à la fois à l'homme photographié et au spectateur (...). Elle recourt pour cela à des stratégies artistiques, celle du photo-montage, mais aussi le mode du texte, affirmant la position du sujet qui parle et celle de l'interlocuteur (...). Alors que la phrase "You are the perfect crime » semble être une accusation, le choix du terme "crime" et non "criminal" renverse la proposition vers une situation de victime. Qui subit le crime et qui l'opère? Seul le fait qu'un crime a lieu, parfait puisque insoupçonné, est ici manifeste. Le message est susceptible de prendre diverses significations, ádrese à la fois à l'homme et au spectateur. Au-delà d'une seule analyse féministe des représentations des genres, cette œuvre questionne les liens entre représentation et nouvoir. au'il s'anit nour Barhara Kruner de s'annronrier nour mieux les nervertir. afin

\subsection{LA SUSTITUCIÓN}

Aunque la tendencia a naturalizar todos los títulos es más propia de las corrientes artísticas anteriores a las vanguardias del XX, aún en día es posible y, en ocasiones, muy necesaria la sustitución porque permite ilustrar, difundir, reclamar un patrimonio histórico o facilitar la tarea del público general a la hora interpretar "las rarezas" del arte posmoderno. Además existen determinadas obras que, debido a su relevancia han entrado a formar parte del corpus de textos básicos del acervo artístico universal. Estos títulos "canonizados" cuentan con sus respectivas versiones en las diferentes lenguas, al igual que los pertenecientes a trabajos plásticos que vieron la luz en épocas anteriores en las que se imponía como norma la traducción. Entre las técnicas de sustitución más comunes en la traducción de títulos de obras de arte destacan: la traducción parcial, el doblete y la traducción total.

En el primero de los casos, se produce una designación mixta de la obra de arte, en la que el título se encuentra a caballo entre dos culturas, mostrando parte de la versión original, transformando y neutralizando la otra, la transparente. Por ejemplo: 
- La dama de Auxerre (ES). The lady of Auxerre (EN). La dame d'Auxerre (FR).

- La maja desnuda (ES). The Naked Maja (EN). La Maja nue (FR)

- El Real Alcázar de Sevilla (ES). The Royal Alcazar of Seville (EN). L'Alcazar de Seville (FR).

- La Madonna del cuello largo (ES). The Madonna with the Long Neck (EN).

En el doblete, sin embargo, se generan títulos bilingües, muy comunes en los artículos de baja especialización publicados en prensa y en las páginas web de algunos museos. Véase, por ejemplo:

- Urban Light (Luz urbana). Chris Burden. "Súperarte”. El País Semanal.

- Injury to Insult to Injury (Agravio para insultar al agravio). En "El matrimonio perfecto. Jake y Dinos Chapman. CAAC Málaga". Arte10.com.

- Naced beyond skin (desnuda más allá de la piel). Xiang Jing. Revista de Verano de El País. 7 de agosto de 2008, pág. 3.

- La corde [the rope]. Masson. National Galleries of Scotland.

- Será lo Mismo (It will be the same). Francisco Goya. Fitzwilliam Museum. Cambdridge.

Por su parte, la traducción total suele estar promovida por una fundación u organismo que difunde la obra de un autor o época determinada en la comunidad lingüística meta. También se lleva a cabo en libros de texto escolares con fines didácticos. Asimismo, suele elegirse como estrategia de mediación para denominar obras que han marcado un hito en la historia del arte universal. Ilustremos estas tres categorías:

1. Traducción promovida por una fundación: MN Centro de Arte Reina Sofía.

- El hombre del cordero. Pablo Picasso.

- Gran perfil de campesina. Julio González.

- Toda la ciudad habla de ello. El gato negro. Eduardo Arroyo.

- Ayudad a España. Joan Miró.

2. Traducción de obras canonizadas.

- Victoria de Samotracia (ES). Winged Victory of Samothrace (EN). Victoire de Samothrace (FR).

- Coliseo (ES). Colosseum (EN). Colisée (FR).

- Laoconte y sus hijos (ES). Laocoon and his sons (EN). Laocoon et ses fils (FR).

3. Traducción de obras de arte contemporáneas en libros de texto escolares: 
- Desnudo bajando por una escalera. Marcel Duchamp.

- Arte como idea. Joseph Kosuth.

- Latas de sopa Campbell. Andy Warhol.

La versión más radical de la traducción completa rebasa los límites del título y se extiende a la propia obra de arte. Este tipo de práctica cada vez se hace más necesaria teniendo en cuenta la proliferación de mensajes lingüísticos en las composiciones que se exportan a culturas muy diferentes. Un caso paradigmático lo hallamos en el arte conceptual. Si partimos de la premisa de que, para este movimiento, las palabras no representan sólo una metáfora del arte sino su verdadera esencia la traducción adquiere una importancia sin parangón cuando este tipo de obras viajan a otros países. El efecto que producen estos trabajos en el público receptor depende casi exclusivamente del traductor (Vidal, 2003).

Topamos aquí con obras que cobran diferente forma según el contexto en que se exponen, instalaciones multilingües en las que conviven varias versiones de un mismo mensaje en diversos idiomas y composiciones narrativas de las que se realizan traducciones al idioma local en formato papel destinadas al público visitante de las exposiciones.

- RE. Thomas Hirschhorn. BIACS 2006, Sevilla. Dentro de la instalación se apilan los siguientes textos en español, francés e inglés: Precariedad, Utopía, La autonomía del arte, El otro, A propósito del Musée Précaire Albinet, A propósito de un trabajo de artista en el espacio público y A propósito del papel del artista en la vida pública. Las traducciones del inglés y francés hacia el español fueron realizadas por Dulce Gamonal.

Installation for Bilbao. Jenny Holzer. Museo Guggenheim de Bilbao. Los aforismos de Instalación para Bilbao (Installation for Bilbao, 1997) inicialmente escritos para un evento que se organizó con el fin de recaudar fondos contra el SIDA- aluden, en euskera, español e inglés, a temas universales como la intimidad, la decepción, la muerte y la pérdida.

\section{REFLEXIONES Y TENDENCIAS}

A la vista de la pequeña muestra que hemos analizado, advertimos, en primer lugar, que el objeto se resiste a una sistematización impecable ya que, en el arte como en la traducción existen mil y una circunstancias que condicionan un determinado resultado.

No obstante, podemos señalar una serie de tendencias apreciadas en la exportación e importación lingüística de arte:

1. Tratamiento diferenciado en la traducción de obras antiguas y modernas en el mundo occidental. Frente a la vitalidad de las obras "recién hechas" o de corta historia, los títulos de composiciones de arte previas a la 
posmodernidad se han calcificado en una versión determinada en cada una de las lenguas y admiten pocas reinterpretaciones. Este hecho se acentúa especialmente en el caso de las obras de autores canónicos que han marcado un hito en la historia del arte universal.

2. El mantenimiento del idioma original en la exportación de arte inyecta nuevos significados a la obra. El empleo de un idioma extranjero obedece a razones comerciales (la compra y venta de arte en las galerías especializadas y en sus sitios web), culturales (uso del Spanglish en el arte chicano), denotativas (localización de un monumento in situ a través de material turístico traducido a excepción del topónimo), intertextuales (inserción de letras de canciones en los títulos de las obras) o de fidelidad con respecto al artista porque, para él, el idioma del título tampoco es materno.

3. El mantenimiento de estrategias de traducción modificadoras en determinados contextos. Los servicios del traductor de arte son requeridos especialmente en cuatro contextos: publicaciones sobre arte a nivel de divulgación, libro de textos escolares, obras de culturas exóticas (aunque se conservan los localismos, se introducen explicaciones de los mismos), y exposiciones promovidas por fundaciones de arte con una determinada política traductora.

4. English-Only. La lengua estrella del arte actual es el inglés. La elección de muchos artistas provenientes de diferentes culturas de este idioma para intitular sus obras es un síntoma claro de su preeminencia en el panorama artístico mundial. Junto a esta tendencia, nos encontramos con un claro posicionamiento de las grandes galerías de arte y de las ferias internacionales a favor de mantener en inglés el título de los trabajos elaborados por artistas de culturas anglosajonas. El fenómeno puede tener varias lecturas: a) que se considere el idioma del título como una pincelada original más en la obra de arte $y$, como tal, intocable; b) que se utilice el inglés para vetar a los receptores ajenos a las esferas artísticas el acceso al intricado mundo del arte contemporáneo; c) que el arte contemporáneo se esté convirtiendo en un mercado de artículos culturales de consumo masivo, como los largometrajes de Hollywood, en el que la moda de mantener los títulos originales también se está imponiendo. Esta última interpretación coincide con el fenómeno de "vulgarización" o "banalización" del arte y la conquista de los museos del street art al que asistimos pero, en apariencia, choca diametralmente con la hipótesis b) en la que se habla de la especialización del inglés como lengua delicatesen de los expertos en este ámbito. Puede que ambos fenómenos no sean incompatibles sino que convivan en perfecta armonía constituyéndose el inglés, al mismo tiempo, en lengua franca del mercado del arte mundial y lengua de moda social cuyo uso va ganando adeptos. Se establece, así, una norma que no debemos perder de vista a la hora de traducir arte para que sea aceptado por la comunidad receptora. 
Lo que, desde aquí, no compartimos es la tendencia a explotar el uso indiscriminado del inglés o de cualquier otro idioma extranjero en el mundo de las exposiciones de arte contemporáneo sin considerar el público al que va dirigida la muestra en cuestión. Esta postura displicente con el receptor produce rechazo, rizando más el rizo de lo "incomprensible" del arte actual; instituciones que se declaran promotoras del arte para la sociedad en general no pueden caer en el error de cerrar la única vía de acceso a la obra que, en ocasiones, sólo tiene el ciudadano de a pie: el título. Máxime, cuando es el autor quien pretende establecer un diálogo directo con el visitante, emocionar, espolearlo. Este es el caso del arte comprometido cuyo mensaje es censurado de manera indirecta con el simple gesto de la no traducción. O el de las corrientes artísticas conceptuales en las que la palabra adquiere una gran importancia como significante, significado, técnica y signo visual. Nos parece contraproducente a este respecto que, justo ahora, cuando las representaciones artísticas huyen del calco de la realidad o fusionan arte y literatura, es decir, cuando existen más motivos de peso para traducir, se olvide hacerlo en determinados contextos en los que todos los elementos que intervienen en el equilibrio de fuerzas del que nace la traducción apunten hacia ello.

\section{BIBLIOGRAFÍA}

CuÉlLar LÁzaro, C (2004): "Estado actual de la investigación en Traducción Onomástica”. En Puntoycoma: Boletín de los traductores españoles de las instituciones de la Unión Europea, $n^{\circ} 89$.

ECO, U (1971): Tratado general de semiótica. Barcelona: Lumen.

FRANCO AIXELÁ, J. (2000): La traducción condicionada de los nombres propios (inglésespañol). Análisis descriptivo. Salamanca: Ediciones Almar.

GArCíA TORRES, M.A: "Comunicación visual". En el sitio web de la empresa Image\&Art. Dirección de Internet:

http://www.imageandart.com/tutoriales/teoria/comunicacion_visual/inde x.html

Goyes NARvÁEZ, J.C. (2002): "Horizontes de la comunicación visual contemporánea". En Espéculo, Revista de estudios literarios. Facultad de Ciencias de la Información de la Universidad Complutense de Madrid, $\mathrm{n}^{\circ}$ 22. Disponible en Internet: http://www.ucm.es/info/especulo/numero22/com visu.html

JiMÉNEZ SERRANO, O. (1996): "Breves notas sobre la traducción al español de los títulos de largometrajes". En L. Félix Fernández, E. Ortega Arjonilla (coord.): Estudios sobre Traducción e Interpretación. Actas de las I Jornadas Internacionales de Traducción e Interpretación de la Universidad de Málaga. 
Mayoral Asensio, R., D. Kelly Y N. Gallardo (1986): "Concepto de 'traducción subordinada' (cómic, cine, canción, publicidad). Perspectivas no lingüísticas de la traducción”. En Pasado, presente y futuro de la lingüística aplicada: actas del III Congreso Nacional de lingüística aplicada. Universidad de Valencia, pp.95-105.

MOYA, V. (2000): La traducción de los nombres propios, Madrid: Cátedra.

MunARi BRUNO (1985): Diseño y comunicación visual. Barcelona: CG Diseño.

Nuez Santana, J.L. (2001): Arte y minorías en los EEUU: el ejemplo chicano. Madrid: Instituto Universitario Agustín Millares de Documentación y gestión Informática.

OrTEga ArjOnilla, E. (2006): "La Traducción del arte: una operación de mediación intercultural "estéticamente" condicionada". En Hikma: Estudios de Traducción-Translation Studies, n 5, pp. 179-199.

---- (2007): "Filosofía, Traducción y Cultura Visual. Un acercamiento intersemiótico a la comunicación intercultural". En Coloquio: Fotografía y cuerpos políticos. Representaciones del cuerpo en la imagen contemporánea. Granada: Instituto de la Paz y Los Conflictos. 25-26 de octubre.

---- (editor) (2007): El giro cultural de la traducción: reflexiones teóricas y aplicaciones didácticas. Frankfurt: Peter Lang.

Rodríguez Bolufé, O (2005): “Tras el hilo de Ariadna: reflexiones en torno al arte chicano". En Nuestra Comunidad, revista semanal de la Universidad Iberoamericana de Ciudad de México, $\mathrm{n}^{\circ}$ 159. Disponible en Internet: http://www.uia.mx/actividades/nuestracom/05/nc159/12.html.

Vidal Claramonte, A. (2003): “(Mis)Translating Degree Zero. Ideology and Conceptual Art”. En M. Calzada Pérez (Ed.): Apropos of Ideology. Manchester: St Jerome, pp 71-87.

Vidal Auladell, F. (2002): “Arte posmoderno y emancipación”. En A Parte Rei. Revista de Filosofía, no 23. Disponible en Internet:

http://serbal.pntic.mec.es/ cmunoz11/posmoderno.pdf.

VIllena Álvarez, I. (2000): Problemática teórico-práctica de la traducción subordinada de cómics. Análisis de un caso práctico: La colección de bistorietas de Astérix en francés y en español. Málaga: Universidad de Málaga, pp 34-109. 